

Article

\title{
Separation of Lithium Ion from Lithium-Cobalt Mixture using Electrodialysis Monovalent Selective Ion Exchange Membrane
}

\author{
Dini Nur Afifah ${ }^{1}$, Teguh Ariyanto ${ }^{1,2, a}$, Supranto $^{1}$, and Imam Prasetyo ${ }^{1,2, b}$ \\ 1 Department of Chemical Engineering, Faculty of Engineering, Universitas Gadjah Mada. \\ Jl. Grafika 2, 55281 Yogyakarta, Indonesia \\ 2 Advanced Material and Sustainable Mineral Processing Research Group, Department of \\ Chemical Engineering, Universitas Gadjah Mada, Jl. Grafika 2, 55281 Yogyakarta, Indonesia \\ Email: ateguh.ariyanto@ugm.ac.id, bimampras@ugm.ac.id (Corresponding authors)
}

\begin{abstract}
Electrodialysis is a separation process which ions are transported through semi permeable membranes under an influence of electric potential. In this research, electrodialysis using monovalent ion exchange membranes was applied to separate lithium ions from mixtures of lithium-cobalt aqueous solution. The study aims to examine factors that affect the performances of electrodialysis monovalent membrane, such as applied voltage, flow rate, and the concentration of cobalt as co-ion. The research was conducted using electrodialysis PC cell BED 64004, monovalent cation exchange membrane (PC-MVK) and monovalent anion exchange membrane (PC-MVA) produced by PCA-PolymerchemicAltmeier, GmbH, Heusweiler, Germany. The effect of applied voltage was studied by varying the voltage in the range of $1-4$ volt/cell volt. The effects of flow rate and initial concentration of ion were studied by changing the flow rate $(10,15$, and $20 \mathrm{~L} / \mathrm{h})$ and varying the ratio of initial concentration between $\mathrm{Li}$ and Co ions (100-100, 100-400, and 100-500 mg/L). The results exhibited that the highest separation capacity of lithium $(99.40 \%)$ was obtained when using the optimum applied voltage of 1 volt/cell. Low energy consumption would be obtained when using a low voltage for the process separation. The optimum flow rate for the lithium separation using electrodialysis monovalent membrane in this research was $15 \mathrm{~L} / \mathrm{h}$. The greater flow rate reduced the current efficiency and increased the energy consumption. When the concentrations of cobalt were increased in the range of $100-500 \mathrm{mg} / \mathrm{L}$, the results indicated a decrease of current efficiency but an increase of energy consumption showing the influence of concentration of cobalt to transportation of lithium ions and selectivity of monovalent membrane.
\end{abstract}

Keyword: Electrodialysis, ion separation, lithium-cobalt ions, monovalent membrane.

ENGINEERING JOURNAL Volume 22 Issue 3

Received 28 October 2017

Accepted 23 March 2018

Published 28 June 2018

Online at http://www.engj.org/

DOI:10.4186/ej.2018.22.3.165 


\section{Introduction}

Lithium ion battery is one of energy storage systems. The properties of Li-ion battery can be seen from its high energy density, light weight battery, low self-discharge, and high durability [1,2]. Due to its favorable characteristics, Li-ion battery is used widely as the energy storage for many kinds of the electronic products and electrical vehicles. Based on the huge application of Li-ion battery, it can be expected that demand of lithium compound as the cathode material and electrolyte will rise rapidly. Nowadays, lithium is produced by extraction of this element from lithium minerals, but unfortunately this is not enough to supply all demand. On the other hand, the increase of battery usage produces a high amount of battery waste, which of course it contains of lithium. Therefore, it is of interest to extract lithium from battery waste. However, aside from the major component, metals like iron $(\mathrm{Fe})$, cobalt $(\mathrm{Co})$, mangan $(\mathrm{Mn})$ and nickel $(\mathrm{Ni})$ could be present in batteries [3]. The methods of lithium recovery, typically, include leaching of metals and then separation process. Some methods used in the lithium recovery processes are solvent extraction [4], precipitation [5], electrochemical [6], adsorption [7], and ion exchange resin [8]. Although all mentioned methods have been widely applied to treat the metal mixture wastewater, they have some drawbacks, such as employing chemicals that trigger formation of sludge, high energy demand, as well as low selectivity [9]. Therefore, it is of interest to develop separation technique which is selective and using less chemicals e.g. electrodialysis.

Electrodialysis is the separation technology that has been introduced since 1950. In the beginning period, electrodialysis was used for demineralisation process of sugar industry [10]. The development in the membrane science then trigger the wide usage of electrodialysis as the separation and purification technology $[11,12,13,14]$. Basically, electrodialysis is the electrochemistry separation method modified by ion exchange membrane. When DC current is applied to the ion exchange membrane, the ion which has similar charge with functional group of ion exchange (co-ion) will be retained by the membrane surface while ion with opposite charge to the membrane surface may across the membrane (counter ion). The product of separation process then flows out from the membrane surface and accumulates in the concentrated compartment $[10$, 15]. The advantages of electrodialysis compared to other methods are the less use of chemicals and ability to separate compounds in small concentrations and low use of energy [11,16]. Studies to recover lithium using electrodialysis have been conducted by several researchers, which typically used standard ion exchange membranes or liquid ion exchange membranes [9, 17, 18, 19].

The challenge in applying electrodialysis is no selectivity for monovalent/polyvalent ions which typically happens when using standard ion exchange membranes. Theoretically, lithium ions and other polyvalent cations cannot be separated by the electrodialysis because the similarity of their charge. Hence, in order to separate lithium from other cations, a modification of electrodialysis processes is needed. The process modification related to lithium separation using electrodialysis is for example combining chelating process of ions and using bipolar membrane [9]. The aim of the chelating agent usage is to form the complex compound between cobalt and chelating agent which has negative charge so that lithium and cobalt can be separated. However, this chelating method causes a membrane fouling, thus decreasing the performance of ion exchange membranes $[9,20]$.

In this work, a membrane of monovalent cation exchange is employed to separate lithium-cobalt in aqueous solution. The ions that can pass the monovalent ion exchange membranes are monovalent ions, while the polyvalent ions will be retained. The use of monovalent cation exchange membrane is predicted to increase the efficiency, effectiveness of process as well as prevent the membrane fouling. Although the monovalent cation exchange membrane is selective to monovalent cation, the polyvalent cations still possible to pass the membrane. The possibility of the polyvalent cations to pass the membranes is depended on some factors, such as ion concentration, applied voltage, $\mathrm{pH}$, membranes, flow rate and the other factors. With the objective to obtain high purity of lithium product, the factor of applied voltage, flow rate, and co-ion concentration (cobalt) were studied and are discussed in this paper.

\section{Materials and Methods}

\subsection{Materials}

Materials used in the study were cobalt nitrate hexahydrate $(99.99 \%)$, lithium nitrate $(99.99 \%)$, lithium hydroxide $(\mathrm{LiOH})(98 \%)$ and sodium sulfate $\left(\mathrm{Na}_{2} \mathrm{SO}_{4}\right)(>99 . \%)$. All chemicals were produced by Merck Millipore, Germany. $\mathrm{LiNO}_{3}$ and $\mathrm{Co}\left(\mathrm{NO}_{3}\right)_{2}$ were used as battery waste model. The electrolyte chamber (5) 
and the product chamber (1) were then filled with $0.25 \mathrm{mg} / \mathrm{L} \mathrm{Na}_{2} \mathrm{SO}_{4}$ as the washing solution and $0.1 \mathrm{mg} / \mathrm{L}$ $\mathrm{LiOH}$, respectively. The types of membranes used in the research were monovalent cation exchange membrane (PC-MVK) and monovalent anion membrane (PC-MVA). The ion exchange membranes were purchased from Polymer Chimie Altmeier GmbH (PCA), Heusweiler, Germany. The characteristic of the membrane used in the research are showed in the Table 1.

Table 1. Characteristics of ion exchange membrane PC Cell BED 64004 (PCA-Polymerchemic Altmeier, GmbH, Heusweiler, Germany).

\begin{tabular}{lccccc}
\hline $\begin{array}{c}\text { Membrane } \\
\text { type }\end{array}$ & $\begin{array}{c}\text { Thickness } \\
(\mu \mathrm{m})\end{array}$ & $\begin{array}{c}\text { Ion exchange } \\
\text { capacity } \\
(\text { mequiv.g- }\end{array}$ & $\begin{array}{c}\text { Chemical } \\
\text { stability }(\mathbf{p H})\end{array}$ & $\begin{array}{c}\text { Functional } \\
\text { Group }\end{array}$ & Permselectivity \\
\hline PC-MVK & 100 & $\mathrm{ca} .1$ & $\mathrm{~N} / \mathrm{A}$ & $\mathrm{N} / \mathrm{A}$ & \\
PC-MVA & 100 & $\mathrm{ca} 1$ & $0-7$ & $\mathrm{~N} / \mathrm{A}$ & $\mathrm{N} / \mathrm{A}$ \\
PC-SK & 130 & $\mathrm{ca} 1$ & $0-11$ & $-\mathrm{SO}_{3} \mathrm{Na}$ & $>0.97$ \\
PC-SA & $90-130$ & ca.1.5 & $0-9$ & $-\mathrm{NR}_{4} \mathrm{Cl}$ & $>0.93$ \\
\hline
\end{tabular}

\subsection{Experimental Procedures}

The experiment was carried out by using laboratory scale Electrodialyzer PC Cell BED 64004 (see scheme in Fig. 1.) The main parts of electrodialyzer PC Cell BED 64004 are chambers, electrode, pumps, membrane module, and direct current generator. The chamber consists of feed chamber (diluate), electrolyte chamber, and concentrate chamber. The stream from each chamber then circulates to the membrane stack inside the module continuously. Membrane module consists of a five-cell membrane that built from repeating section of monovalent cation exchange membrane (PC-MVK), spacer, and monovalent anion exchange membranes (PC-MVA), called membrane stack. The function of spacer between the cation exchange membrane and anion exchange membrane is to arrange the diluate and concentrate stream. The maximum flow rate and applied voltage can be applied to the electrodialyzer is $20 \mathrm{~L} / \mathrm{h}$ and 20 volts. The specification of membrane is shown in Table 2.

Table 2. Specification of Membrane Module PC Cell BED 64004.

\begin{tabular}{ll}
\hline Characteristic & Size \\
\hline Effective membrane area & $64 \mathrm{~cm}^{2}$ \\
Membrane size & $6 \times 4 \mathrm{~cm}$ \\
Spacer type & - Thickness $=45 \mu \mathrm{m}$ \\
& - Material = silicone/polypropylene \\
& - Mesh type $=45 ”$ \\
Processing length & $8 \mathrm{~cm}$ \\
Nominal flowthrough/cell & $8 \mathrm{~L} / \mathrm{h}$ \\
Membrane per unit & $60 \mathrm{max}$ pcs \\
Effective membrane area/unit & $0.38 \mathrm{~m}^{2}$ \\
\hline
\end{tabular}




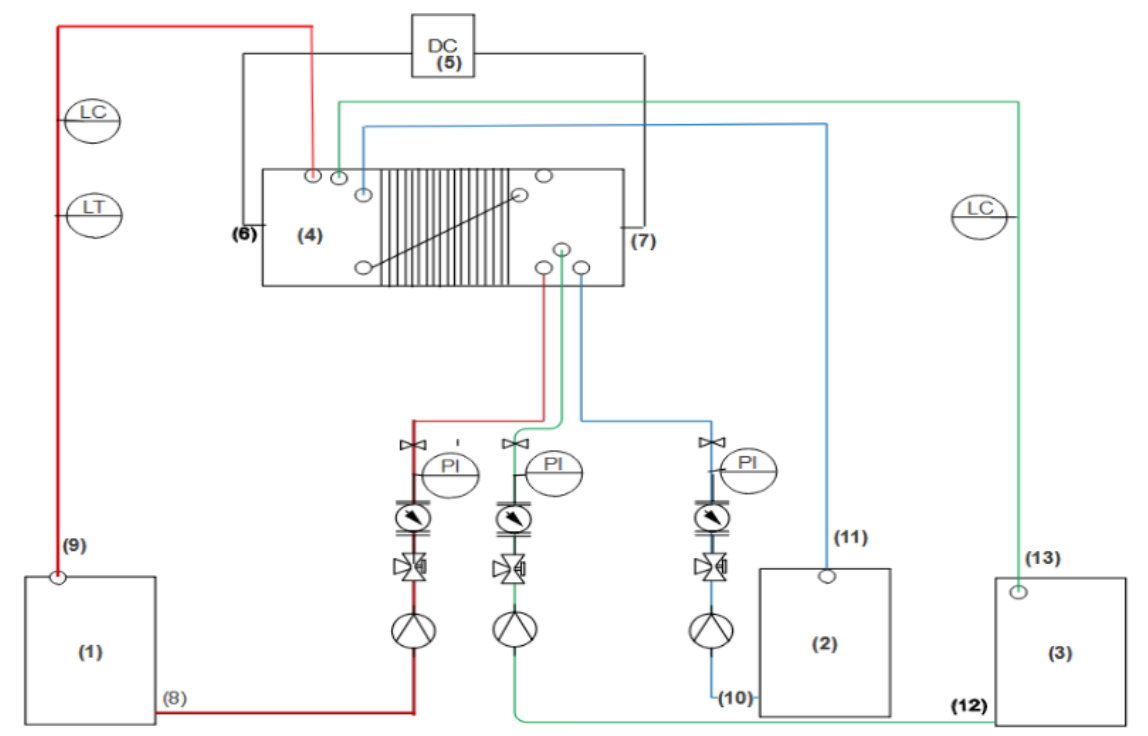

1. Feed chamber

2. Concentrate chamber

3. Electrolyte chamber

4. Membrane module

5. Direct current generator

6. Anode

7. Cathode

8. Feed stream out

9. Feed stream in

10. Concentrate stream out

11. Concentrate stream in

12. Electrolyte stream out

13. Electrolyte stream in

Fig. 1. Scheme of electrodialyzer PC Cell BED 64004 (Figure adapted from PC Cell BED 64004's Manual Book)

The procedures are as follows. The feed solution contained $100 \mathrm{mg} / \mathrm{L}$ of lithium ion and $300 \mathrm{mg} / \mathrm{L}$ of cobalt ion was placed into the feed chamber (see (1) in Fig. 1). The electrolyte chamber (3) and the product chamber (2) were then filled with $0.25 \mathrm{mg} / \mathrm{L} \mathrm{Na}_{2} \mathrm{SO}_{4}$ as the washing solution and $0.1 \mathrm{mg} / \mathrm{L} \mathrm{LiOH}$, respectively. Volume of solution for each tank was $380 \mathrm{ml}$. The electric current generated by DC power supply was applied to electrodialyzer. At certain time, a $2 \mathrm{~mL}$ solution in the feed tank and the product was taken for analysis. Samples were analyzed by Inductively Coupled Plasma-Atomic Emission Spectroscopy (ICP-AES) (Perkin Elmer OPTIMA7000DV) to determine the concentration of lithium and cobalt ions. The influences of applied voltage and flow rate to the performances of separation were studied by varying the voltage in the range of 5-20 volts and the flow rate between 5-20 L/h, respectively. Concentrations of lithium and cobalt ions in the solution were varied i.e. 100, 400 and $500 \mathrm{mg} / \mathrm{L}$ to determine the effect of ion concentration on the performances of electrodialyzer. The flow rate of electrode rinse and concentrate compartment was equal to the flow rate of diluate compartment (feed chamber). To study the effect of applied voltage, the flow rate of the both compartments was set to $20 \mathrm{~L} / \mathrm{h}$. When studying the effect of flow rate, the flow rate both compartments were varied in the range of $5-20 \mathrm{~L} / \mathrm{h}$. To study the co-ion concentration, the flow rate was set to $20 \mathrm{~L} / \mathrm{h}$. The principle separation of lithium from the mixture solution using electrodialysis was shown in the Fig. 2.

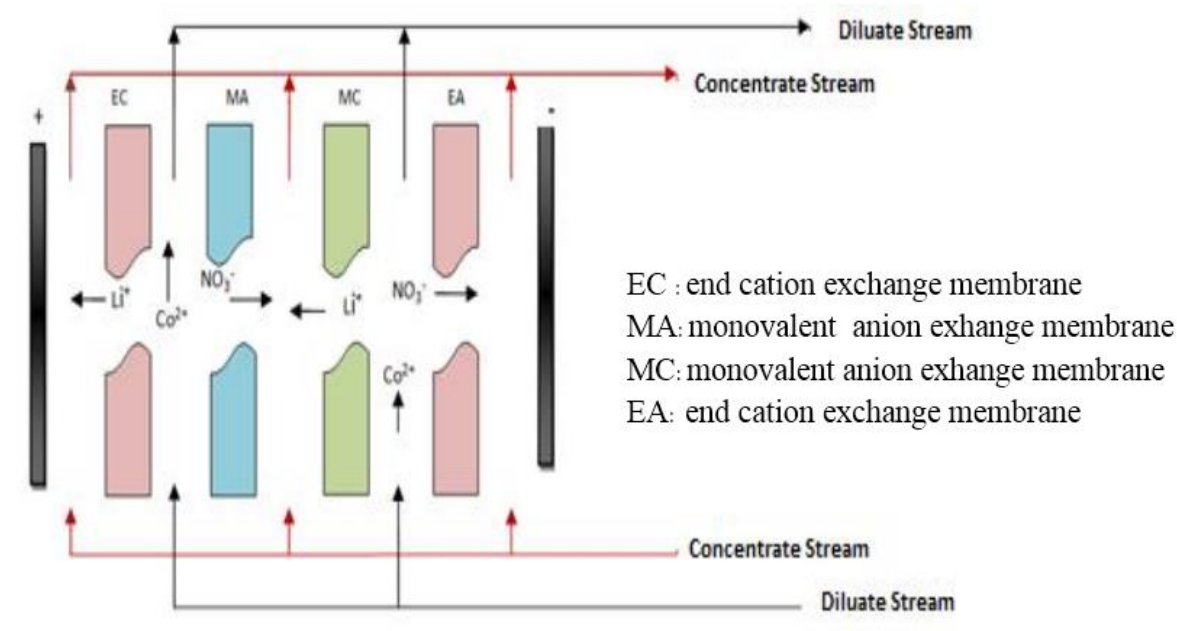

Fig 2. Principle of lithium separation using electrodialysis monovalent ion exchange membrane. 


\subsection{Membrane Characterizations}

The membrane characterizations were conducted to study morphology of membrane surface and to analyze the functional groups of ion exchange membranes. The morphology of the membrane surface was taken by JEOL JSM-6510 LA Spectroscopy Electron Microscope. The functional group of membrane was characterized by using Fourier Transform Infra-Red (FTIR) analysis by Shimadzu. For FTIR, a spectrum range between 500 and $4000 \mathrm{~cm}^{-1}$ was taken with scan rate of 20 infrared spectra per second. The data recorded were used without any background subtraction.

\subsection{Data Analysis}

The concentration of lithium and cobalt determined by ICP-AES was employed to calculate the performance parameters of electrodialysis i.e. separation capacity of lithium $\left(\% P_{L i}\right)$, the purity of product, current efficiency $(C E)$ and energy consumption $(E)$.

\subsubsection{Separation capacity of ion $\left(\% P_{L i}\right.$ and $\left(\% P_{C o}\right)$}

Lithium recovery by electrodialysis was expressed as the separation capacity of lithium $\left(\% P_{L i}\right)$. The separation capacity of lithium was calculated by Eq. (1).

$$
(\% P)=\frac{M i-M f}{M f} \times 100 \%
$$

where $M_{i}$ is the mole of ion in the initial time ( $\mathrm{mmol}$ ), and $M_{f}$ is the mole of ion at specified interval time (mmol).

\subsubsection{Energy consumption (E)}

Energy consumption is defined as the amount of electrical energy used to separate one gram of $\mathrm{Li}^{+}$from the feed solution. Equation (2) is used to determine the energy consumption.

$$
E=\frac{U \int_{0}^{t} I d t}{N_{R}}
$$

where $E$ is the energy consumption ( $\mathrm{kWh} /$ gram $\left.\mathrm{Li}^{+}\right), U$ is the electric potential (volt), $I$ is the current (A), $N_{R}$ is the number of ion (mole) transferred from the diluate chamber, and $t$ is the operation time (s)

\subsubsection{Current efficiency $(C E)$}

The current efficiency is defined as the ratio of ions that can be separated from the feed solution to the total electrical charge applied to the cell of membrane. The equation to calculate the value of current efficiency is shown by Eq. (3) [19].

$$
C E=\frac{\left(n_{t}-n_{0}\right) \cdot z \cdot F}{\int_{0}^{t} I(t) d t} \times 100
$$

The symbol of $n_{t}$ in Equation (3) states the moles of ion in the diluate tank at time $t(\mathrm{~s})\left(\mathrm{mol} \mathrm{L}^{-1}\right), z$ is the absolute valence ion, $I$ is the current (A), $t$ is the operating time (s), and $F$ is the Faraday constant (96485 A s $\left.\mathrm{mol}^{-1}\right)$.

\section{Results and Discussion}

\subsection{Membrane Characterizations}

To study the surface morphology, SEM image of the monovalent cation exchange membrane (PC-MVK) was taken and it is compared to the standard cation exchange membrane (PC-SK). Figures 3(a) and 3(b) show the morphology of PC-MVK and PC-SK. Figure 3 reveals that the PC-MVK membrane has smoother surface 
than the PC-SK membrane. Membrane surface will affect the separation properties of membrane. A smooth and uniform surface could increase e.g. electrical resistance of the membrane [21]. In electrochemical processes, electrical resistance will affect the energy consumption, so that the ion exchange membranes with low electrical resistance are desirable [22].

Functional groups of PC-MVK and PC-MVA determined by FTIR are showed in Fig. 4. For comparison, a standard cation (PC-SK) and anion (PC-SA) exchange membranes were characterized and are discussed. The PC-MVK membrane (Fig. 4(b)) exhibits a similar functional group like PC-SK (Fig. 4(a)). On the other hand, PC MVA (Fig. 4(d)) membrane tends to have similar functional group to PC-SA (Fig. 4(b)). The bands at $1180.49 \mathrm{~cm}^{-1}, 1125.51 \mathrm{~cm}^{-1}$, and $1037.75 \mathrm{~cm}^{-1}$ are the typical of IR adsorption for sulfonate group $\left(-\mathrm{SO}_{3} \mathrm{H}\right)$ $[23,24]$. The sulfonate group is one kind of the functional groups in the cation exchange membrane besides $-\mathrm{COO}^{-},-\mathrm{PO}_{3}^{2-},-\mathrm{PO}_{3} \mathrm{H}^{-}$, and $-\mathrm{C}_{6} \mathrm{H}_{4} \mathrm{O}^{-}$[25]. The band for adsorption of $\mathrm{N}$ and $\mathrm{H}$ from quaternary ammonium group for PC-SA (Fig. 4(c)) and PC-MVA (Fig. 4(d)) can be seen at wavelength number 841.96 $\mathrm{cm}^{-1}$ and $879.58 \mathrm{~cm}^{-1}$. Peak areas at $1610-1650 \mathrm{~cm}^{-1}$ and $1460-1470 \mathrm{~cm}^{-1}$ are the IR adsorption for C-N vibration of quaternary ammonium which is the common functional group of anion exchange membrane. The other functional group of anion exchange membrane are $-\mathrm{NH}_{3}{ }^{+},-\mathrm{NRH}_{2}{ }^{+},-\mathrm{NR}_{2} \mathrm{H}^{+}$, and $-\mathrm{PR}_{3}{ }^{+}$[15]

\subsection{The Influence of Applied Voltage}

Applied voltage is a major factor that affects the electrodialyzer performances. The applied voltage plays a role in the current formation of potentiostatic process. The current accumulation different is the driving force of the transport the ions across the membranes [26]. To study the influence of applied voltage in the lithium separation process, the voltage was varied in the range of 5-20 volts while the initial concentration of ions was kept constant $(100 \mathrm{mg} / \mathrm{L}$ lithium and $300 \mathrm{mg} / \mathrm{L}$ cobalt). The lithium separation process was examined using five stacks of cells, hence the amount of voltage that flew in each cell equals to 1, 2, 3, and 4 volt/cell, respectively. First insight is that a higher applied voltage reduces the operation time of electrodialysis. It can be noticed from Figure 5 (the separation performance vs. time) that when using 1 volt/cell, a 90 -minutes separation time is needed to obtain $95 \% \mathrm{Li}$ purity. In contrast when using a higher voltage of $2 \mathrm{volt} / \mathrm{cell}$, the separation time drops to ca. 20 minutes. Increasing voltage further results in a similar separation time which indicates an optimum voltage to trigger the driving force separation was achieved [27-29].

Figure 5 presents the influence of applied voltage to separation capacity of lithium $\left(\% P_{L_{i}}\right)$ from the mixture solution. Based on the figure, the lithium separation capacity increased with the applied voltage from 1 to 2 volts/cell. The lithium separation capacity when 1 and 2 volts/cell of voltage applied to the system were $98.63 \%$ and $99.40 \%$. When applied voltage was further increased to 3 and 4 volts/cell, the lithium separation capacity decreased slightly to $99.40 \%$ and $99.02 \%$, respectively. Based on results, the separation capacity of lithium $\left(\% P_{L i}\right)$ as the function of applied voltage $(v)$ can be expressed by second order polynomial equation which is showed by Eq. (4), with factor $\left(R^{2}\right)$ of 0.911 . The trend of an increase of the separation performance of ions when using a higher voltage agrees with previous study [27].

$$
\% P_{L i}, \mathrm{f}\{v\}=-0.010 v^{2}+0.275 v+97.540
$$



(a)

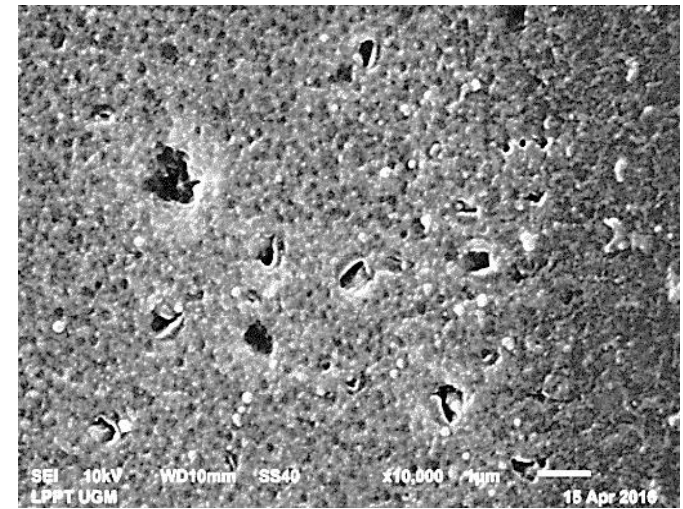

(b)

Fig. 3. (a) SEM images of monovalent cation exchange membrane (PC-MVK) and (b) standard cation exchange membrane (PC-SK). 




(a)

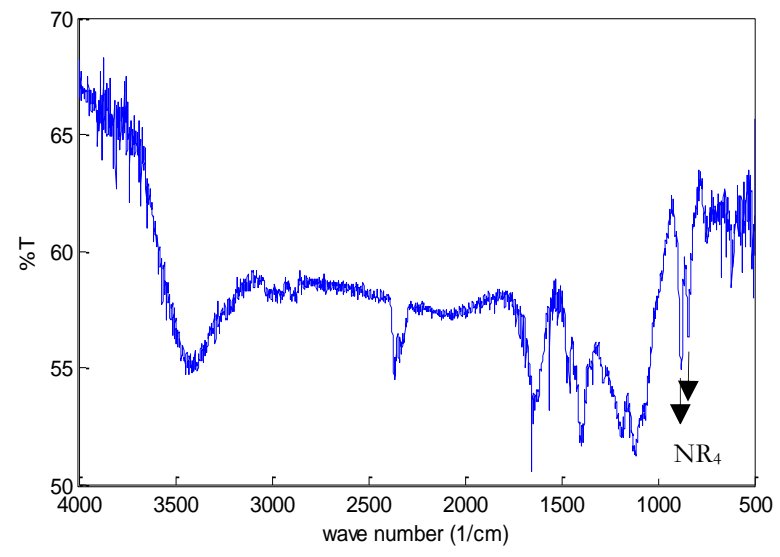

(c)

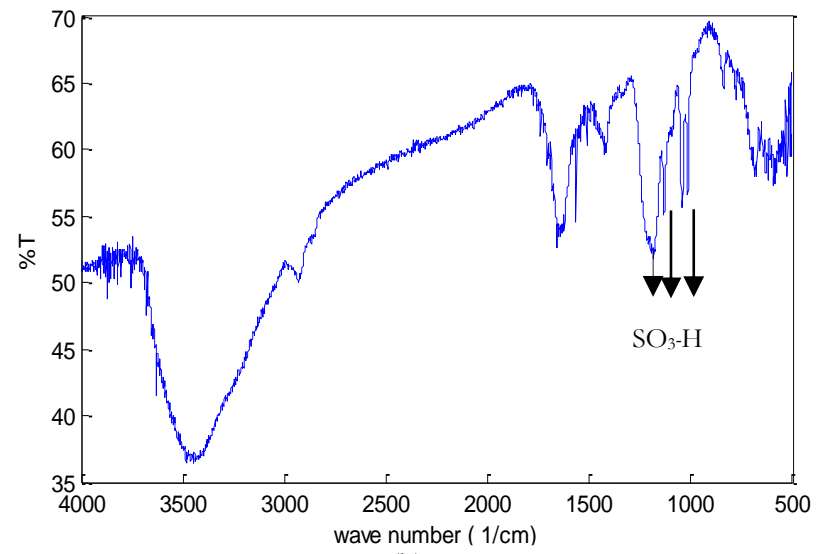

(b)

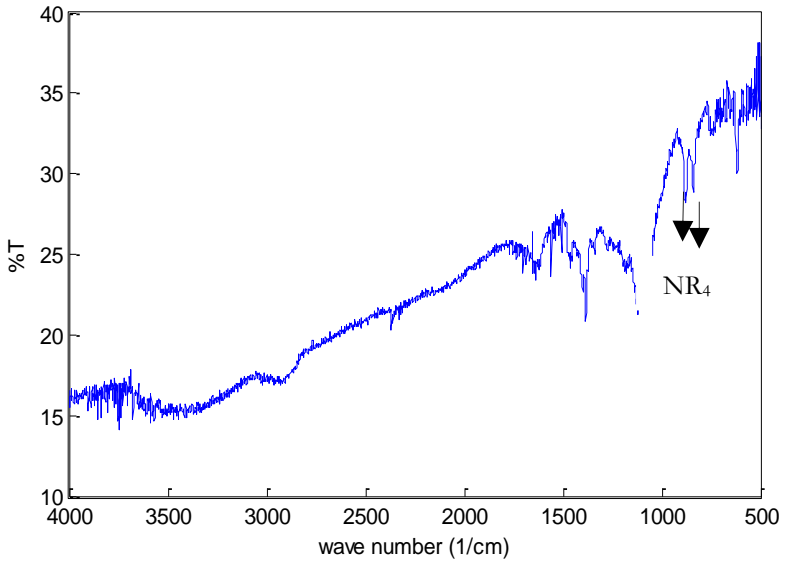

(d)

Fig. 4. FTIR signals of (a) PC-SK, (b) PC-MVK, (c) PC-SA and (d) PC-MVA.

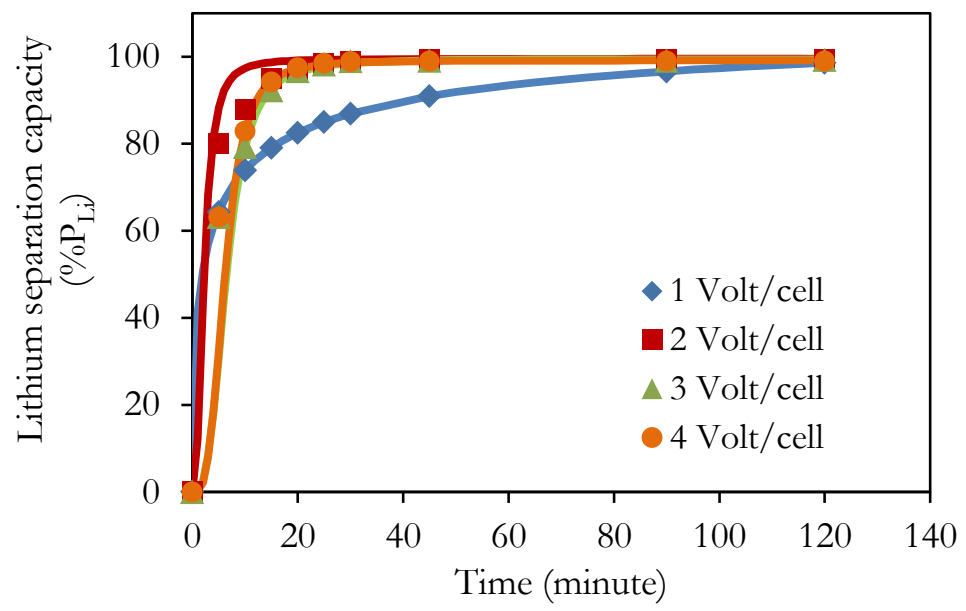

Fig. 5. The effect of applied voltage to the separation capacity of lithium. Conditions: $100 \mathrm{mg} / \mathrm{L}$ lithium and $300 \mathrm{mg} / \mathrm{L}$ cobalt solution and $15 \mathrm{~L} / \mathrm{h}$ flow rate.

The phenomenon can be explained since there is a competition between lithium and cobalt to pass through the cation exchange membranes when electrodialysis was carried out with a voltage exceeding the limiting current density (Fig. 6(a) of the current vs applied voltage). In general, cobalt which has hydrated radii larger than lithium will move toward the cathode faster than lithium, in the high applied voltage. Besides 
hydrated radii, the electronegativity of ion also affects the mobility of ions when high applied voltage is applied. Cobalt which has greater electronegativity than lithium will be attracted to cathode side strongly. The higher voltage results in a faster movement of cobalt to the cathode. Therefore, it will increase the possibility of cobalt leakage to the lithium product chamber then reduce the purity of lithium product. Besides hydrated radii, the electronegativity of ion also affects the mobility of ions when high applied voltage is applied. Cobalt which has greater electronegativity than lithium will be attracted to cathode side strongly. The higher the voltage, the faster of cobalt movement to the cathode. The research result (Fig. 6(b)) shows that the amount of cobalt which pass the cation membranes increase from 0.297 to $0.526 \mathrm{mmol}$, when the process used applied voltage greater than 1 volt/cell. The more cobalt ion content contaminates lithium product, the less of product purity. The purity of the lithium product when using 1,2, 3, and 4 volts/cell were $91.38 \%, 95.73 \%$, $93.69 \%$, and $88.38 \%$.

Besides reducing the purity of lithium product, another consequence of process using applied voltage greater than $1 \mathrm{volt} / \mathrm{cell}$ is the increases of energy consumption (Fig. 6(c)). The electrical energy consumed in the process of electrodialysis with the voltage of 1,2, 3 and 4 volts/cell were 10.07, 55.19, 105.66 and 192.16 $\mathrm{kWh} /$ gram Li+ . Based on those results, it can be stated that the amount of energy consumed increased linearly when the applied voltage was increased from 1 up to 4 volts/cell. Equation (5) can explain the increases of energy consumption as the function of applied voltage, with $R^{2}$ of 0.974 .

$$
E, f\{v\}=59.67 v-58.41
$$

In line with the increases of energy consumption, the energy efficiency was decreased when the process used applied voltage greater than 1 volt/cell (Fig. 6(d)). The current efficiency for the process using applied voltage of $1,2,3$ and 4 volts/cell were $37.75 \%, 14.06 \%, 10.96 \%$, and $8.06 \%$. The decreasing of current efficiency $(E C)$ as the function of applied voltage (V) is stated by Eq. (6), with $R^{2}$ of 0.975 .

$$
(E C), \mathrm{f}(v)=205.7 v^{-1.09}
$$

The electrodialysis process performed on a very high electrical voltage causes the faster ion transfer from the bulk to the surface of the membrane than the transfer of ions across the membrane. Thus, there is a formation of ion depletion area in the place adjacent to the membrane and also accumulation ion at membrane surface, called concentration polarization [28]. The depletion area adjacent of membrane is the place where the splitting of water molecules to $\mathrm{OH}^{-}$and $\mathrm{H}^{+}$takes place. Both of those ions move toward the surface of the membrane faster than the other ions. The consequence is the increases of $\mathrm{pH}$ around the surface of the membrane that cause salt precipitation in the anion exchange membrane surface [34]. Moreover, the effect of $\mathrm{pH}$ value increases is the deposition of a metal ions in the membrane surface that cause the losses of membrane performance called membrane fouling $[10,11]$. When the electrodialysis process was conducted with electric voltage over the limiting current, the decrease of current efficiency indicates that the electric current is used for other processes, such as water splitting, back diffusion of ion from concentrated to diluate compartment, and co-ion transfer [19].

The result showed that the optimum applied voltage to separate mixture solution contains $100 \mathrm{mg} / \mathrm{L}$ lithium and $300 \mathrm{mg} / \mathrm{L}$ cobalt is 1 volt/cell. The higher voltage will increase the cobalt ion capability to pass the membrane then accumulate in the lithium product chamber, so that the purity of product and electrical efficiency of lithium separation decrease. 


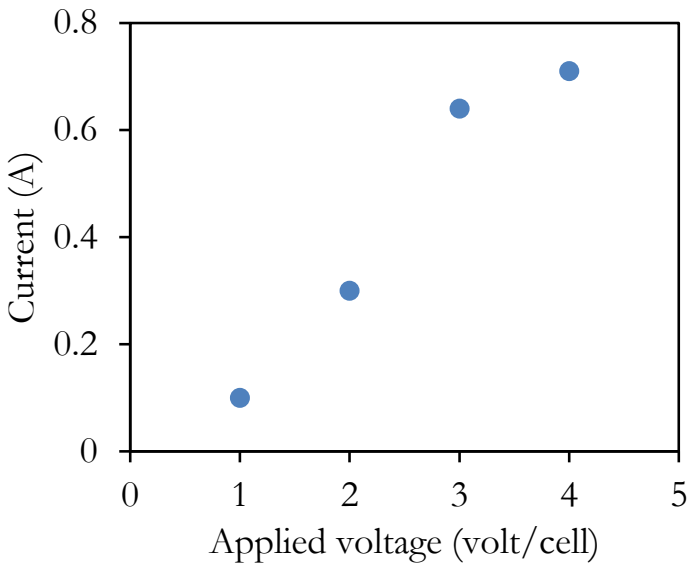

(a)



(c)

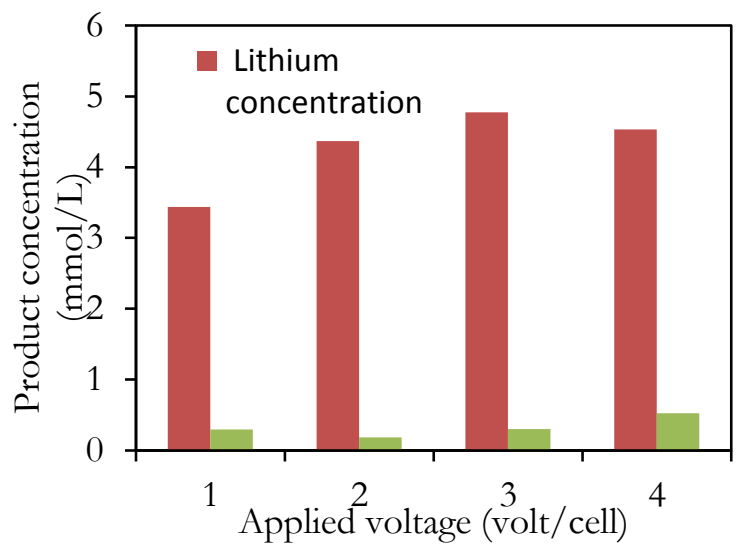

(b)

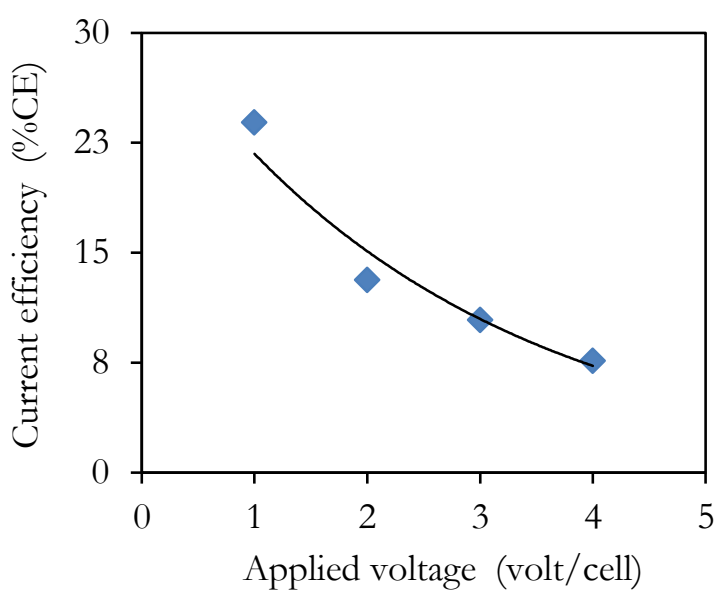

(d)

Fig. 6. The effect of applied voltage to the current (a), product purity (b), energy consumption (c), and current efficiency (d). Conditions: $100 \mathrm{mg} / \mathrm{L}$ lithium and $300 \mathrm{mg} / \mathrm{L}$ cobalt solution and $15 \mathrm{~L} / \mathrm{h}$ flow rate.

\subsection{The Influence of Co-ion Concentration}

It is known that cobalt presents in the Li-ion battery [30]. Typically, the ratio of lithium:cobalt in the Li-ion battery are (1:3), (1:4), and (1:5) [31]. Then, it is expected that there are variations of ions in the battery wastewater where the concentration of cobalt ion is higher than lithium. To investigate the influence of cobalt concentration to the membrane selectivity the concentrations of cobalt in the feed solution were varied to 100, 400, and $500 \mathrm{mg} / \mathrm{L}$, while the concentration lithium was set to $100 \mathrm{mg} / \mathrm{L}$. Figure 7 shows that lithium separation capacity increased in a logarithmic manner with the increasing number of cobalt ions. The lithium separation capacity $\left(\% P_{L i}\right)$ when the concentration of cobalt in the feed solution varied to 100,400 , and 500 $\mathrm{mg} / \mathrm{L}$ were $97.95 \%, 98.18 \%$, and $98.207 \%$, respectively. The increasing of lithium separation capacity, when using a high concentration of cobalt, can be explained by the fact that the increase of cobalt concentration in the solution results in higher feed concentration and conductivity. The high conductivity of solution will reduce the electrical resistance on the membrane surface, so that the mobility of ion is getting faster in the beginning. In the end of process, the conductivity of solution drops due to lower concentration. Thus, makes an increase of the electrical resistance arise, hence slowing ion transportation [34]. The equation expressing the correlation between lithium separation capacity $\left(\% P_{L i}\right)$ and concentration of cobalt $\left(C_{c o}\right)$ is showed by Eq. (7), with $\mathrm{R}^{2}$ of 0.919 .

$$
\% P_{L i}, \mathrm{f}\left(C_{C o}\right)=0.25 \ln \left(C_{C o}\right)+97.96
$$




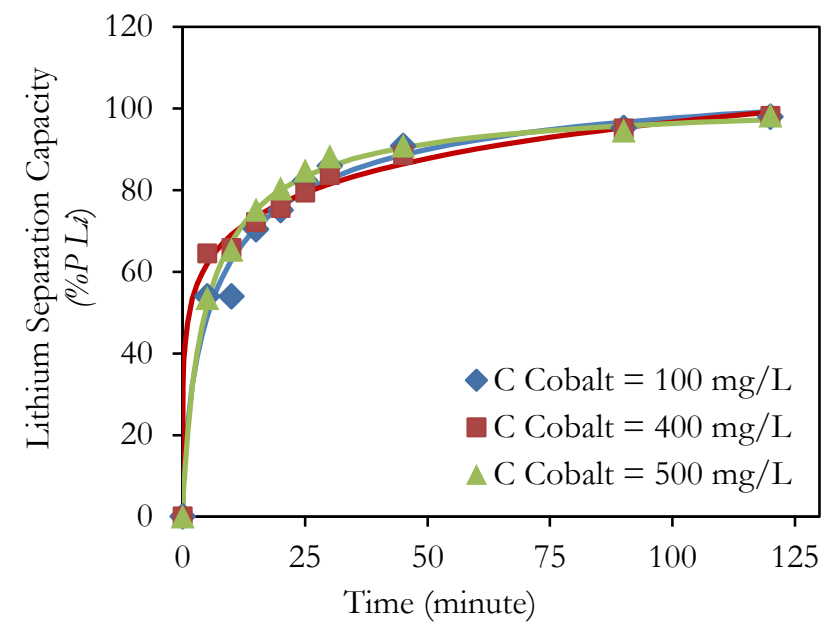

Fig. 7. The effect of cobalt ion concentration to the separation capacity of lithium. Conditions: 5 volt applied voltage and $20 \mathrm{~L} / \mathrm{h}$ flow rate.

Although the separation capacity of lithium increased due to the higher concentration of cobalt, the purity of lithium product decreased with the increasing of cobalt concentration. The purities of lithium product in the electrodialysis were $94.09 \%$ (100 mg/L Co), 79.97\% (400 mg/L Co) and 84.67\% (500 mg/L Co) (Fig. 8(a)). The previous explanation stated that cobalt has bigger hydrate radii than lithium. The ion having bigger hydrate radii will bind more water molecules than the small ones. The results are cobalt will be attracted to the membrane surface. Although some chemicals and treatments have been added to increase the repulsive force, they cannot work when the concentration of ion is very high. Therefore, the more cobalt ions can penetrate to the membrane surface which consequences to a reduction of the ion separation capacity and purity of lithium product [33,34].

The decreases of current efficiency increased the energy consumption during separation process that shown by Fig. 8(b). The figure shows that energy demand to separate lithium increase linearly as the function of cobalt ion concentration in the feed solution. The energy consumption when the concentration of cobalt was varied to 100,400 , and $500 \mathrm{mg} / \mathrm{L}$, were $6.44 \mathrm{kWh} / \mathrm{gram} \mathrm{Li} \mathrm{Li}^{+}, 18.06 \mathrm{kWh} / \mathrm{gram} \mathrm{Li}+, 21.67 \mathrm{kWh} / \mathrm{gram}$ $\mathrm{Li}^{+}$. The equation showing the correlation of increased energy consumption $(E)$ as a function of cobalt ion concentration $\left(C_{C_{0}}\right)$ is shown by Eq. (8), which the value of $\mathrm{R}^{2}$ is 0.995 .

$$
E C, \mathrm{f}\left(C_{C_{0}}\right)=-19.2 \ln \left(C_{C_{0}}\right)+134.7
$$

Besides affecting the purity of separation product, the concentration of cobalt also influences the current efficiency of process. The decreasing of current efficiency as the function of the cobalt ion concentration is showed by curve on Fig. 8(c) (data: 46.22\% (100 mg/L), 18.06\% (400 mg/L) and 16.12\% (500 mg/L). The data can be well fitted with a logarithmic equation (Eq. (9)).

$$
E, \mathrm{f}\left(C_{C_{o}}\right)=0.04\left(C_{C_{o}}\right)+2.64
$$

The $R^{2}$ value of Eq. (9) is 0.999 . 


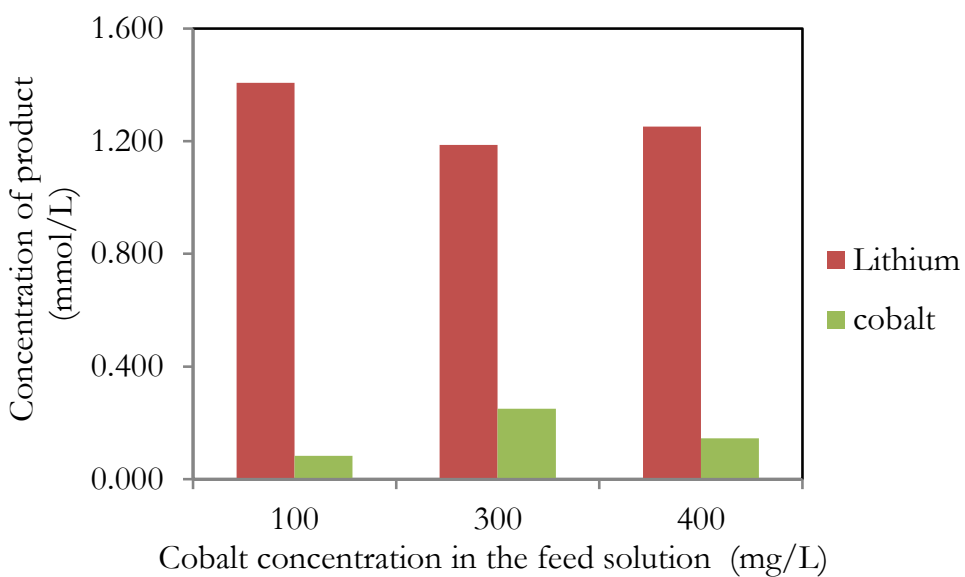

(a)

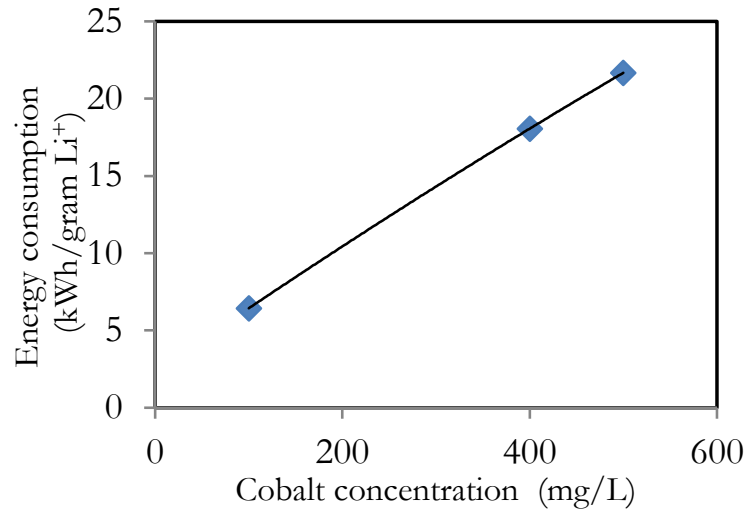

(b)



(c)

Fig. 8. The effect of cobalt ion concentration to the product purity (a), energy consumption (b) and current efficiency (c). Conditions: $5 \mathrm{~V}$ applied voltage and $20 \mathrm{~L} / \mathrm{h}$ flow rate foreach compartment.

\subsection{The Influence of Flow Rate}

The effect of flow rate to the separation of lithium using electrodialysis was studied by varying the flow rate to 10 (Re: 0.0039), 15 (Re: 0.0058), and $20 \mathrm{~L} / \mathrm{h}$ (Re: 0.0076). Those of the flow rate were used to separate mixture containing $100 \mathrm{mg} / \mathrm{L}$ lithium and $300 \mathrm{mg} / \mathrm{L}$ cobalt. Applied voltage used in this study was 5 volts. Figure 9 shows how flow rate affects the lithium separation capacity $\left(\% P_{L i}\right)$. The graph shows that the separation capacity of lithium increased from $66.63 \%$ to $70.91 \%$ when flow rate was increased from $10 \mathrm{~L} / \mathrm{h}$ to $15 \mathrm{~L} / \mathrm{h}$. The decreasing of lithium separation capacity to $59.22 \%$ occurred when the flow rate was enlarged to $20 \mathrm{~L} / \mathrm{h}$. The result showed that the higher flow rate may increase the separation capacity of process, but when the process is conducted using flow rate higher than $20 \mathrm{~L} / \mathrm{h}$ the separation capacity of ion decreased. Those trend reveals that the flow rate affect the separation capacity of ions in polynomial manner. Equation (10) shows the equation that can be used to describe the lithium separation capacity of lithium $\left(\% P_{L i}\right)$ as the function of flow rate $(L)$.

$$
\% P_{L i}, \mathrm{f}\{L\}=0.034 L^{2}+1.101 L+89.68
$$

with $R^{2}$ of 1.000 


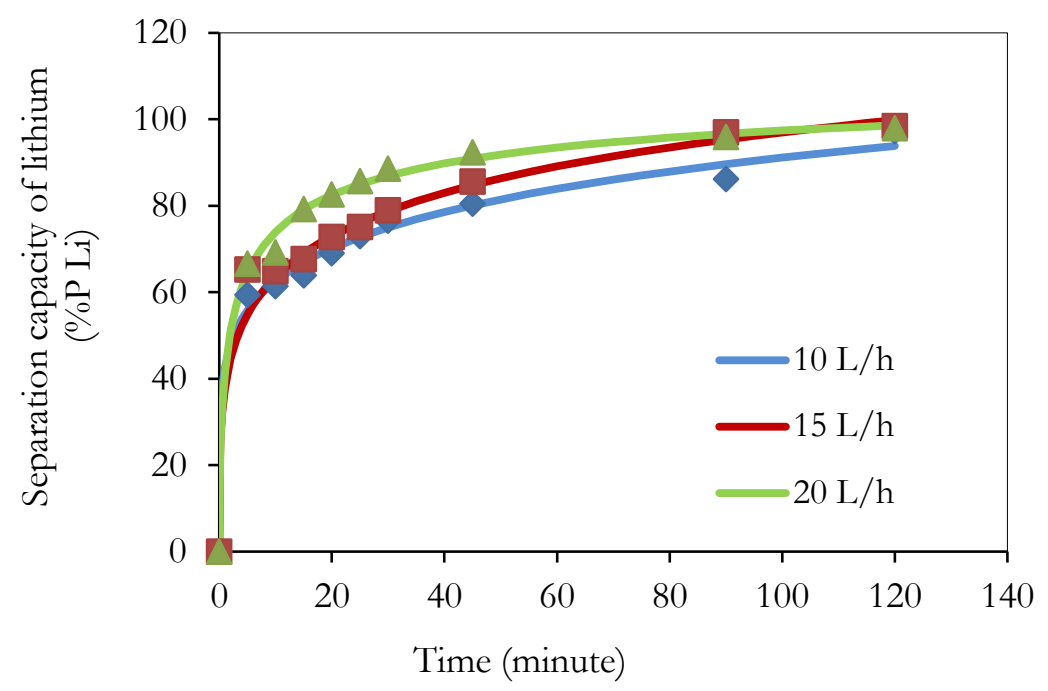

Fig. 9. The effect of flow rate on the separation capacity of lithium. Conditions: $100 \mathrm{mg} / \mathrm{L}$ lithium and 300 $\mathrm{mg} / \mathrm{L}$ cobalt solution and 1 volt/cell. Conditions: 5 volts applied voltage and $100 \mathrm{mg} / \mathrm{L}$ and $300 \mathrm{mg} / \mathrm{L}$ concentration of lithium and cobalt.

The influence of the flow rate to the current efficiency was shown in Fig. 10(a). The graph shows that the current efficiency increased when the flow rate of $10 \mathrm{~L} / \mathrm{h}$ was increased to $15 \mathrm{~L} / \mathrm{h}$. The increase of current efficiency was from $66.63 \%$ to $70.91 \%$. Based on research results, the current efficiency (EC) as the function of flow rate $(L)$ of can be expressed by second order polynomial equation, with $R^{2}$ of 1.000 (Eq. (11)).

$$
E C, \mathrm{f}\{L\}=-0.319 L^{2}+8.840 L+10.16
$$

The current efficiency will affect the amount of energy used during the separation process. If the current efficiency increases, energy consumption will decrease, and vice versa. The data of research showed that the current efficiency increased when the flow rate was increased from $10 \mathrm{~L} / \mathrm{h}$ to $15 \mathrm{~L} / \mathrm{h}$ (Fig. 10(b)). This resulted to the decrease of energy used during the process from $4.12 \mathrm{kWh} / \mathrm{gram} \mathrm{Li} \mathrm{Li}^{+}$to $3.96 \mathrm{kWh} / \mathrm{gram} \mathrm{Li} \mathrm{Li}^{+}$. In the other hand, when the flow rate was increased to $20 \mathrm{~L} / \mathrm{h}$, the energy consumption increased to 4.85 $\mathrm{kWh} /$ gram $\mathrm{Li}^{+}$. Based on those results, the optimum flow rate to separate $100 \mathrm{mg} / \mathrm{L}$ of lithium and 300 $\mathrm{mg} / \mathrm{L}$ of cobalt was $15 \mathrm{~L} / \mathrm{h}$. Equation (12) showed the correlation between flow rate and energy consumption.

$$
E, \mathrm{f}\{L\}=0.021 L^{2}-0.567 L+7.684
$$

with the $\mathrm{R}^{2}$ of 1.00

The result trend in this study is in-line with the other research using electrodialysis for zinc separation [34]. The result showed that current efficiency increased when the separation of zinc conducted using flow rate in the range of 4 to $7 \mathrm{~L} / \mathrm{h}$. When flow rate greater than $7 \mathrm{~L} / \mathrm{h}$, the performances of zinc separation process decreased. Hence, there is an optimum flow to obtain maximum current efficiency as well as energy consumption.

The optimum flow rate is present in electrodialysis which can be explained as follows. Flow rate of the feed affects the thickness of the thin film layer formed between bulk liquid and membrane surface [34]. The greater the flow rate, the thinner film layer adjacent the membrane. A thin film layer makes mass transfer resistance smaller, thus the number of separated ion increases [22]. In accordance with the following explanation, it can be estimated that the increases in the flow rate of $10 \mathrm{~L} / \mathrm{h}$ to $15 \mathrm{~L} / \mathrm{h}$ in the lithium separation process can reduce the thickness of the film, so that the rate of lithium's transfer process was faster, and the number of separated ions increased. Although rapid flow rate increases the separation, a very high flow rate will decrease the efficiency of the separation. The decrease of current efficiency in the lithium separation is because of the short contact time between ions and membranes [11]. The increase of the current efficiency when the flow rate was increased to $15 \mathrm{~L} / \mathrm{h}$ occurred is due to a lower resistance on membrane as 
the effect of decreasing film thickness. Thereby, the separation capacity of lithium rises $[27,35,36]$. When the flow rate increased into $20 \mathrm{~L} / \mathrm{h}$, the separation capacity of lithium declined to $59.22 \%$. The decreasing of the separation capacity occurred because the residence time of the ion inside the membrane module was very short, so that the separation capacity of lithium declined [11, 34].

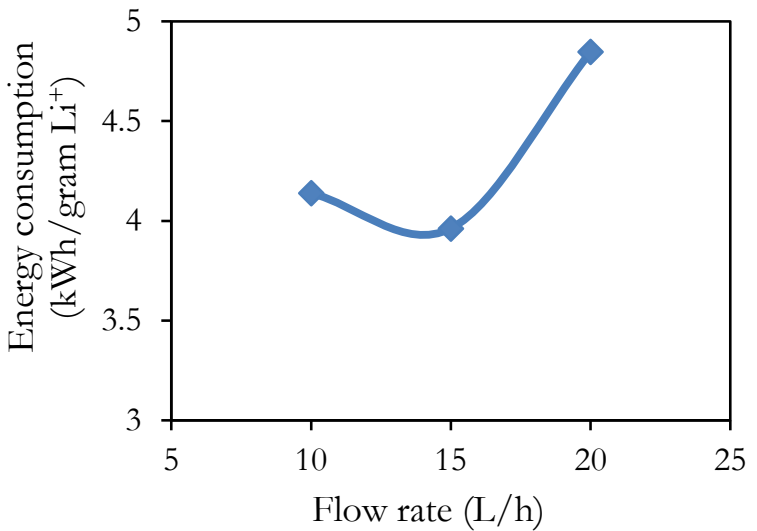

(a)

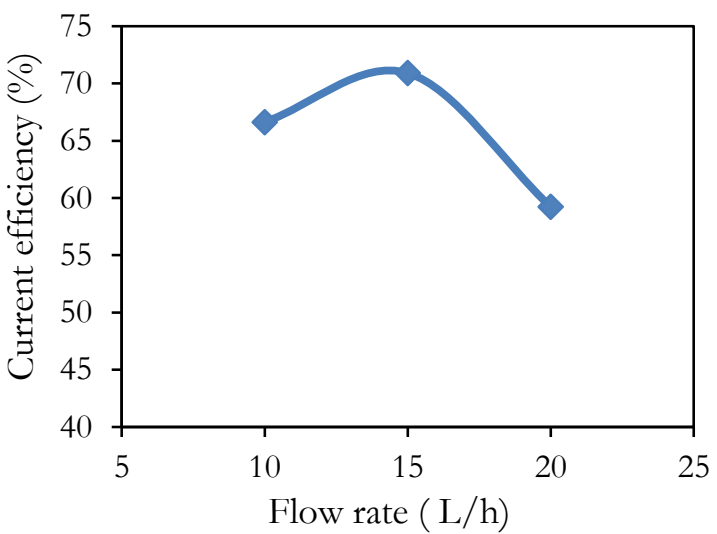

(b)

Fig. 10. The effect of flow rate to the energy consumption (a) and current efficiency (b). Conditions: 100 $\mathrm{mg} / \mathrm{L}$ lithium and $300 \mathrm{mg} / \mathrm{L}$ cobalt solution and 1 volt/cell.

\section{Conclusions}

Electrodialysis using monovalent membranes was employed to separate lithium ions from lithium-cobalt solution. The factors that affect the separation process are applied voltage, flow rate, and cobalt ion concentration. Applied voltage affects the driving force of lithium separation. In order to obtain high product concentration, the voltage applied to the process should be set to the optimum condition. The best applied voltage to separate the mixture of $100 \mathrm{mg} / \mathrm{L}$ lithium and $300 \mathrm{mg} / \mathrm{L}$ cobalt is 5 volts (1 volt/cell). Flow rate affects the contact time between membrane surface and ion. The suitable flow rate in this research is $15 \mathrm{~L} / \mathrm{h}$. A higher flow rate reduces the current efficiency and increases the energy consumption. The cobalt ion concentration in the feed solution affects the selectivity of monovalent ion exchange membrane. The highest purity of lithium obtained was $95.73 \%$ when using 1 volt/cell applied voltage, $15 \mathrm{~L} / \mathrm{h}$ flow rate and $100 \mathrm{mg} / \mathrm{L}$ lithium-300 mg/L cobalt solution.

\section{Acknowledgements}

The authors thank the funding from Lembaga Pengelola Dana Pendidikan (LPDP), Ministry of Finance, Republic of Indonesia through Mobil Listrik Nasional (Molina) Grant.

\section{References}

[1] W. Chen, H. Liang, Z. Qi, K. Shao, J. Shu, and Z. Wang, "Enhanced electrochemical properties of lithium cobalt titanate via lithium-site substitution with sodium," Electrochim. Acta, vol. 174, pp. 12021215, 2015.

[2] M. Oswal, J. Paul, and R. Zhao, "A comparative study of ion-lithium baterry," University of Southern Califonia, 2010.

[3] S. G. Zhu, W. He, G. M. Li, X. Zhou, X. J. Zhang, and J. W. Huang, "Recovery of Co and Li from spent lithium ion-batteries by combination method of acid leaching and chemical precipitation," Trans. Nonferrous Met. Soc. China, vol. 22, pp. 2274-2281, 2012.

[4] J. Kang, G. Senanayake, J. Sohn, and S. M. Shin, "Recovery of cobalt sulfate from lithium ion battery by reductive leaching and solvent extraction with Cyanex 272," Hydrometallurgy, vol. 100, pp. 168-171, 2010. 
[5] P. Meshram, B. D. Pandey, and T. R. Mankhand., "Extraction of lithium from primary and secondary sourced by pre-treatment, leaching and separation: A comprehensive review," Hydrometallurgy, vol. 150, 192-208, 2014.

[6] C. Lupi, M. Pasquali, and A. Dell'Era, "Nickel and cobalt recycling from lithium ion batteries by electrochemical processes," Waste Management, vol. 25, pp. 215-220, 2005.

[7] Md. R. Awual, M. Ismael, and T. Yaita, "Efficient detection and extraction of cobalt (II) from lithium ion batteries and wastewater by novel composite adsorbent," Sens. Actuators, B, vol. 191, pp. 9- 18, 2014.

[8] S. M. Badawy, A. A. Nayl, R. A. El Khashab, and M. A. El-Khateeb, "Cobalt separation from waste mobile phone batteries using selective precipitation and chelating resin," J. Mater. Cycles Waste Manag., vol. 16, pp. 739-746, 2014.

[9] A. Iizuka, Y. Yamashita, H. Nagasawa, A. Yamasaki, and Y. Yanagisawa, "Separation of lithium and cobalt from waste lithium-ion batteries via bipolar membrane electrodialysis coupled with chelation," Sep. Purif. Technol, vol. 113, pp. 33-41, 2013.

[10] M. Peraki, E. Ghanzanfari, G. Pinder, and T. F. Harrington, "Electrodialysis: An aplication for the environmental protection," Separation and Purification Technology, vol. 161, pp. 96-103, 2016.

[11] G. Lee, "Effect operating parameters on the removal performance of electrodialysis for treating wastewater containing cadmium," Desalin. Water Treat., vol. 35, pp. 150-157, 2011.

[12] F. Wilhelm, Bipolar Membrane Electrodialysis. Enschede: Twente University Press, 2011

[13] E. Gain, S. Laborie, Ph. Viers, M. Rakib, G. Durand, and D. Hartmann, "Ammonium nitrate wastewater treatment by coupled membrane electrolysis and electrodialysis," J. Appl. Electrochem., vol. 32, pp. 969975, 2002.

[14] Y. Fukumoto and K. Haga, "Advanced treatment of swine wastewater by electrodialysis with a tubular ion exchange membrane," Anim. Sci. J., vol. 75, no. 5, pp. 479-485, 2004.

[15] M. N. A. Pirkanniemmi, "Electroactive Ion Exchange Membrane," Department of Chemical Engineering, Abo Akademi Univesity, Finland, 2012.

[16] R. C. A. Moura, D. A. Bertuol, C. A. Ferreira, and F. D. R. Amado, "Study of chromium removal by the electrodialysis of tannery and metal-finishing effluents," Inter. J. Chem. Eng., vol. 2012, pp. 1-7, 2012.

[17] C. Jiang, W. Y. Wang, Q. Wang, H. Feng, and T. Xu, "Production of lithium hydroxide from lake brines through electro-electrodialysis with bipolar membranes (EEDBM)," Ind. Eng. Chem. Res, vol. 53, pp. 6103-6122, 2014.

[18] T. Hoshino, "Lithium recovery from seawater by electrodialysis using ionic liquid-based membrane technology," ECS Trans., vol. 58, pp. 173-177, 2014.

[19] N. Parsa, A. Moheb, A. Mehrabani-Zeinabad, and M. A. Masigol, "Recovery of lithium ions from sodium-contaminated lithium bromide solution by using electrodialysis process," Chem. Eng. Res. Des., vol. 98, pp. 81-88, 2015.

[20] A. J. Chaudary, J. D. Donalson, S. M. Grimes, and N. G. Yasri, "Separation of nickel from cobalt using electrodialysis in the presence of EDTA," J. Appl. Electrochem., vol. 30, pp. 439-445, 2000.

[21] L. Zarybnicka, E. Stranska, J. Machotova, and G. Lencova, "Preparation of two layer anion-exchange poly(ethersulfone) based membrane: Effect of surface modification," Institute of Chemistry and Technology of Macromolecular Materials, Faculty of Chemical Techology, University of Pardubice, Czech Republic, 2016.

[22] Y. Tanaka, H. Uchino, and M. Murakami, "Continuous ion-exchange membrane electrodialysis of mother liquid discharged from a salt-manufacturing plant and transport of $\mathrm{Cl}^{-}$ions and $\mathrm{SO}_{4}{ }^{2-}$ ions," Membrane Water Treatment, vol. 3, pp. 63-76, 2012.

[23] J. Zhang, D. P. Wilkinson, H. Wang, and S. Liu, "FTIR and electrochemical observation of water content reduction in a thin nafion ${ }^{\circledR}$ film induced by an impregnation of metal complex cations," Electrochim. Acta, vol. 50, pp. 4082-4088, 2005.

[24] P. Morrissey and D. Vesely, "Stability of sulphonate type membranes in aqueous bromine/bromide environments," J. Membr. Sci., vol. 247, pp. 169-178, 2005.

[25] T. Sata, "Ion exchange membrane, preparation, characterization, modification and application," The Royal Society of Chemistry, Science Park, Milton Road, Cambridge, 2004.

[26] Y. Zheng, Z. Li, X. Wang, X. Gao, and C. Gao, "The treatment of cyanide from gold mine effluent by a novel five-compartment electrodialyis," Electrochim. Acta, vol. 169, pp. 150-158, 2015.

[27] M. Sadrzadeh, A. Kaviani, and T. Mohammadi, "Mathematical modelling of desalination by electrodialyisis," presented at The Tenth International Water Technology Conference, IWTC10 2006, Alexandria, 2007. 
[28] G. Lee, "Effects of operating parameters on the removal performance of electrodialysis for treating wastewater containing cadmium," Desalin. Water Treat., vol. 35, no. 1-3, pp. 150-157, 2011.

[29] N. Arahman, S. Mulyati, M. R. Lubis, and R. Takagi, "The removal of fluoride from water based on applied current and membrane types in electrodialysis," J. Fluorine Chem., vol. 191, pp. 97-102, 2016.

[30] J. Wang, M. Chen, H. Chen, T. Luo, and Z. Xu, "Leaching study of spent li-ion batteries," Procedia Environ. Sci., vol. 16, pp. 443-450, 2012.

[31] A. Fadel, R. Lafi, A. Aouni, A. Hafiane, and S. Nacef, "Separation of zinc ions from synthetically prepared brackish water using electrodialysis: effect of operating parameters," Desalin. Water Treat., vol. 57, pp. 1-9, 2015.

[32] C. V. Gerasihm, J. Křivčík, and P. Mikulášek., "Investigation of batch electrodialysis process for removal of lead ions from aqueous solutions," Chem. Eng. J., vol. 256, pp. 324-334, 2014.

[33] H. Li, H. Meng, C. Li, and L. Li, "Competitive transport of ionic liquids and impurity ions during the electrodialyisis process," Desalination, vol. 245, pp. 349-356, 2009.

[34] N. Kabay, O. Arar, S. Samatya, U. Yuksel, and M. Yuksel, "Separation of fluoride from aqueous solution by electrodialysis: Effect of process parameter and other ionic species," J. Hazard. Mater, vol. 153, no. 1-2, pp. 107-113, 2008.

[35] K. H. Choi and T. Y. Jeoung, "Removal of zinc ions in wastewater by electrodialysis," Korean J. Chem. Eng., vol. 19, pp.107-113, 2002.

[36] M. B. S. Ali, D. J. Ennigrou, AND B. Hamrouni, "Iron removal from brackish water by electrodialysis," Environ. Technol., vol. 34, no. 17, pp. 2521-2529, 2013. 